\title{
Lactate, a putative survival factor for myeloma cells, is incorporated by myeloma cells through monocarboxylate transporters 1
}

\author{
Shiho Fujiwara', Naoko Wada', Yawara Kawano', Yutaka Okuno', Yoshitaka Kikukawa', Shinya Endo', \\ Nao Nishimura ${ }^{1}$, Nina Ueno ${ }^{1}$, Hiroaki Mitsuya ${ }^{1}$ and Hiroyuki Hata ${ }^{1,2^{*}}$
}

\begin{abstract}
Background: Lactate levels within tumors are correlated with metastases, tumor recurrence, and radioresistance, thus apparently contributing to poor outcomes in patients with various cancers. We previously reported that high-level production of lactate by multiple myeloma (MM) cell lines is associated with high-level LDH activity within such MM cells. However, the kinetics of lactate remains to be studied. In the present study, we attempted to elucidate the mechanism of lactate incorporation into MM cells.

Methods: Six MM cell lines and stromal cells obtained through long-term culture of bone marrow samples from MM patients were employed. Incorporation of lactate was quantified using $C^{14}$-labeled lactate. The role of MCT1, a member of the monocarboxylate transporters (MCTs), expressed on MM cells, was examined in the presence of its inhibitor (a-cyano-4-hydroxycinnamic acid: $\mathrm{CHC}$ ) and by using gene-silencing technique.

Results: MM cell lines as well as stromal cells were found to produce lactate. Incorporation of $C^{14}$-labeled lactate into MM cells occurred in all 6 MM cell lines analyzed. Inhibition of MCT1 by using CHC or MCT1-targeting siRNA reduced lactate incorporation and caused apoptosis in MM cells. This apoptosis was enhanced when the activity of pyruvate dehydrogenase kinase was blocked by dichroloacetate. Survival of normal peripheral blood mononuclear cells was not influenced by MCT1 inhibition.

Conclusions: The present data suggest that lactate is produced by MM cell lines and stromal cells, and contributes to the survival of such MM cells in autocrine or paracrine manners. Suppression of lactate incorporation by targeting MCT1 may provide a novel therapeutic strategy for MM which may be applicable for other B-cell neoplasms.
\end{abstract}

Keywords: Multiple myeloma, Glucose, Lactate, Monocarboxylate transporters

\section{Background}

It has been reported that the growth of certain cancer cells is dependent on aerobic glycolysis to obtain ATP efficiently via glycolysis under hypoxic conditions, ultimately leading to the production of lactate by cancer cells [1]. It has also been reported that elevated lactate levels within tumors are correlated with the incidence of metastases [2,3], tumor recurrence, radioresistance [4], and poor prognosis [5].

\footnotetext{
* Correspondence: hata@kumamoto-u.ac.jp

'Department of Hematology, Kumamoto University School of Medicine,

1-1-1, Honjo, Chu-ouku, Kumamoto city, Kumamoto 860-8556, Japan

${ }^{2}$ Graduate School of Health Sciences, Faculty of Medical Sciences, Division of

Informative Clinical Sciences, Kumamoto University School of Medicine,

4-24-1 Kuhonji, Kumamoto 862-0976, Japan
}

Lactate is transported through monocarboxylate transporters (MCTs), which are composed of 14 members and encoded by the SLC16 gene family. Among the MCTs, only four isoforms (MCT1-MCT4) are known as proton-linked transporters. MCT1 has a superior affinity for lactate compared with MCT4, and therefore MCT1 is considered to facilitate lactate uptake, whereas MCT4 is considered to export lactate from inside cells [5-8]. The functional expressions of MCT1 and MCT4 are regulated by CD147 (basigin), which is essential for trafficking and anchoring MCTs in plasma membranes [9-11]. MCT1 is expressed in most tissues and various cancer cells (e.g., colon, breast, lung, prostate, stomach) [5,12], 
and MCT1 inhibition decreases the intracellular $\mathrm{pH}$, resulting in cell death [13].

We previously reported that genes related to aerobic glycolysis are upregulated in MM cells, and that myeloma cells produce large amounts of lactate in correlation with expression of the $L D H$ gene [14]. However, accumulating evidence indicates that lactate produced by cancer cells is incorporated into the cancer cells themselves as a fuel for oxidative phosphorylation $[15,16]$. Doherty [16] et al. reported that lactate is produced by stromal cells and supplied to oxidative cancer cells, which is known as the reverse Warburg effect. Similar finding was reported in diffuse large B-cell lymphoma by Martinez et al., showing that production of lactate from lymphoma associated stroma cells and lactate incorporation to lymphoma cells [17]. These previous reports strongly indicate that lactate is not an energy waste, but instead is actively incorporated into cells and contributes to the survival of solid tumors or B-cell neoplasms. However, to date, there have been no reports showing the incorporation of lactate into myeloma cells. Thus, in the present study, we investigated the kinetics of lactate in myeloma cells and its importance for the survival of myeloma cells.

\section{Results}

Expression of lactate transporters and lactate incorporation into MM cells

Expressions of MCT1 and CD147 were detected at various levels in myeloma cell lines by western blotting (Figure 1A and $\mathrm{B}$ ). Analyses of lactate incorporation into myeloma cells showed that lactate was indeed incorporated into all myeloma cell lines at various levels (Figure 1C).

Next, we analyzed how lactate was incorporated into myeloma cells. To elucidate the contribution of MCT1 to lactate incorporation, the expressions of MCT1 or CD147 were inhibited by siRNA transfection (Figure 2A and B). MCT1 knockdown led to a significant reduction in lactate incorporation, while CD147 knockdown did not result in a reduction in lactate incorporation (Figure 2C), suggesting a contribution of MCT1 to lactate incorporation into myeloma cells.

\section{MCT1 inhibition induces apoptosis}

Because we found that lactate was incorporated into myeloma cells, we hypothesized that incorporated lactate may serve as an energy resource for myeloma cells, and therefore that myeloma cells may undergo apoptosis when there is a shortage of lactate within the cells. To prove this hypothesis, we used $\mathrm{CHC}$, a competitive inhibitor of MCT1, to investigate whether it induces apoptosis in myeloma cell lines by inhibiting lactate incorporation. As expected, $\mathrm{CHC}$ induced apoptosis in a dose-dependent manner (Figure 3A). However, $\mathrm{CHC}$ did not show cytotoxicity toward normal peripheral blood mononuclear cells (PBMCs) (Figure 3B). We confirmed the cytotoxic activity of $\mathrm{CHC}$ toward myeloma cells isolated from $\mathrm{MM}$ patients and found significant induction of apoptosis by $\mathrm{CHC}$ (Figure 3C). Subsequently, we utilized MCT1knockdown cells to further confirm the role of MCT1 in the survival of myeloma cells. As shown in Figure 3D, significant induction of apoptosis was found upon MCT1 mRNA inhibition. However, CD147 knockout did not contribute to apoptosis (data not shown).

\section{Increased cytotoxic effect of $\mathrm{CHC}$ with a glycolysis inhibitor}

Next, we investigated the effect of combined treatment of DCA, which theoretically reduces lactate production by inhibiting pyruvate dehydrogenase kinase, with $\mathrm{CHC}$. We considered that the combination of DCA with $\mathrm{CHC}$ should accelerate lactate reduction within myeloma cells and eventually lead to enhancement of apoptosis. As expected, this combined treatment caused a significant increase in apoptosis in the myeloma cell line KMM-1 (Figure 4).

\section{Discussion}

We previously reported that aerobic glycolysis is operational in myeloma cells [14] and observed that significant amounts of lactate were produced by myeloma cells as a result of glycolysis. However, lactate is not a wasted metabolite, but can be considered as an important energy source for cancer cells $[6,15,16,18,19]$. Doherty et al. [16] reported that lactate is supplied to cancer cells from the surrounding environment, and referred to this phenomenon as the reverse Warburg effect. We have shown that lactate was clearly incorporated into myeloma cells and that this incorporation was mediated by MCT1. We also observed production of lactate by bone marrow stromal cells (data not shown), suggesting that the reverse Warburg effect might be applied to the microenvironment in MM as previously reported in B-cell lymphoma [17]. Taking these hypotheses together, we further suggest that lactate may serve as an autocrine energy resource, because it is both produced and incorporated by myeloma cells (Figure 5 ).

However, the mechanisms that regulate lactate kinetics are still not well established. We found that CD147 knockdown did not influence lactate uptake or induce apoptosis, suggesting that CD147 is not required for lactate kinetics. Additionally, we found that MCT1 knockdown decreased lactate uptake, and thus consider that lactate is incorporated by MCT1, but not through CD147. However, other investigators reported that both $\mathrm{CD} 147$ and MCT1 are responsible for proliferation of myeloma cells and exportation of lactate [13], suggesting that the exact roles of these molecules in lactate transport remain controversial.

Given the accumulation of reports showing MCT1 expression in various cancer cells (e.g. breast, colon, and lung cancer) and its correlation with poor prognosis 


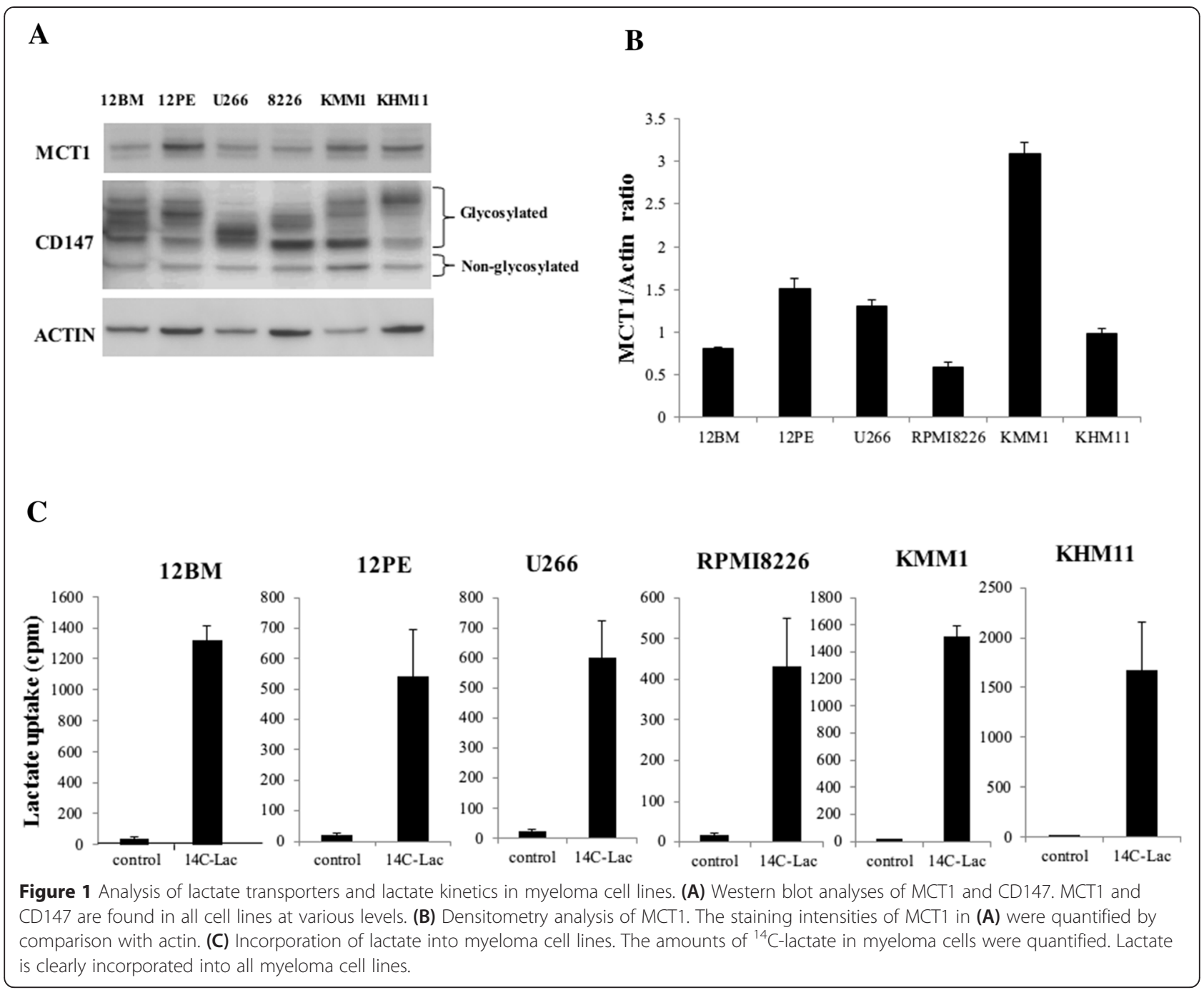

$[2,3,5,20,21]$, these previous reports indicate that MCT1 should play an important role for the survival of myeloma cells. Walters et al. [13] also reported that MCT1 mRNA expression levels were significantly higher in MM plasma cells than MGUS plasma cells, and that MCT1 expression was correlated with resistance to chemotherapy. Because MCT1 was reported to be regulated by c-Myc in some cancer cells [22-25], and MYC dysregulation was caused by complex translocation or insertion as a late progression event in MM, MCT1 could be induced in advanced MM under the control of c-Myc. Given that MCT1 could be an adverse prognostic factor, we consider that MCT1 could be a good therapeutic target for advanced MM.

$\mathrm{CHC}$, a competitive inhibitor for MCT1, was reported to show anticancer effects in various cancer cells [15,26-28]. In a previous report, $\mathrm{CHC}$ was found to inhibit mitochondrial respiration and decrease cell growth through inhibition of cellular pyruvate uptake [29]. Zhao et al. [26] reported that $\mathrm{CHC}$ suppressed tumor growth of osteosarcoma in vitro and in vivo through regulation of the NF-kB pathway. Moreover, they reported that $\mathrm{CHC}$ enhanced the efficacy of conventional chemotherapeutic agents. Another report showed that $\mathrm{CHC}$ contributed to chemosensitization against cisplatin in a colon cancer cell line [28]. However, there are no reports showing antitumor effects of $\mathrm{CHC}$ for myeloma cells. In this study, CHC induced apoptosis in myeloma cells, but did not exhibit cytotoxicity toward normal PBMCs, indicating that MCT1 could be a safe therapeutic candidate molecule. Moreover, because we found augmentation of cytotoxicity by $\mathrm{CHC}$ with DCA, cooperative inhibition of the glucose metabolic pathway could be a useful option.

Our results indicate that modification of lactate kinetics, such as targeting of MCTs by antibody-based chemotherapeutic reagents, could be an attractive modality to control the growth of myeloma cells although the target of this modality may be limited for some subsets of 


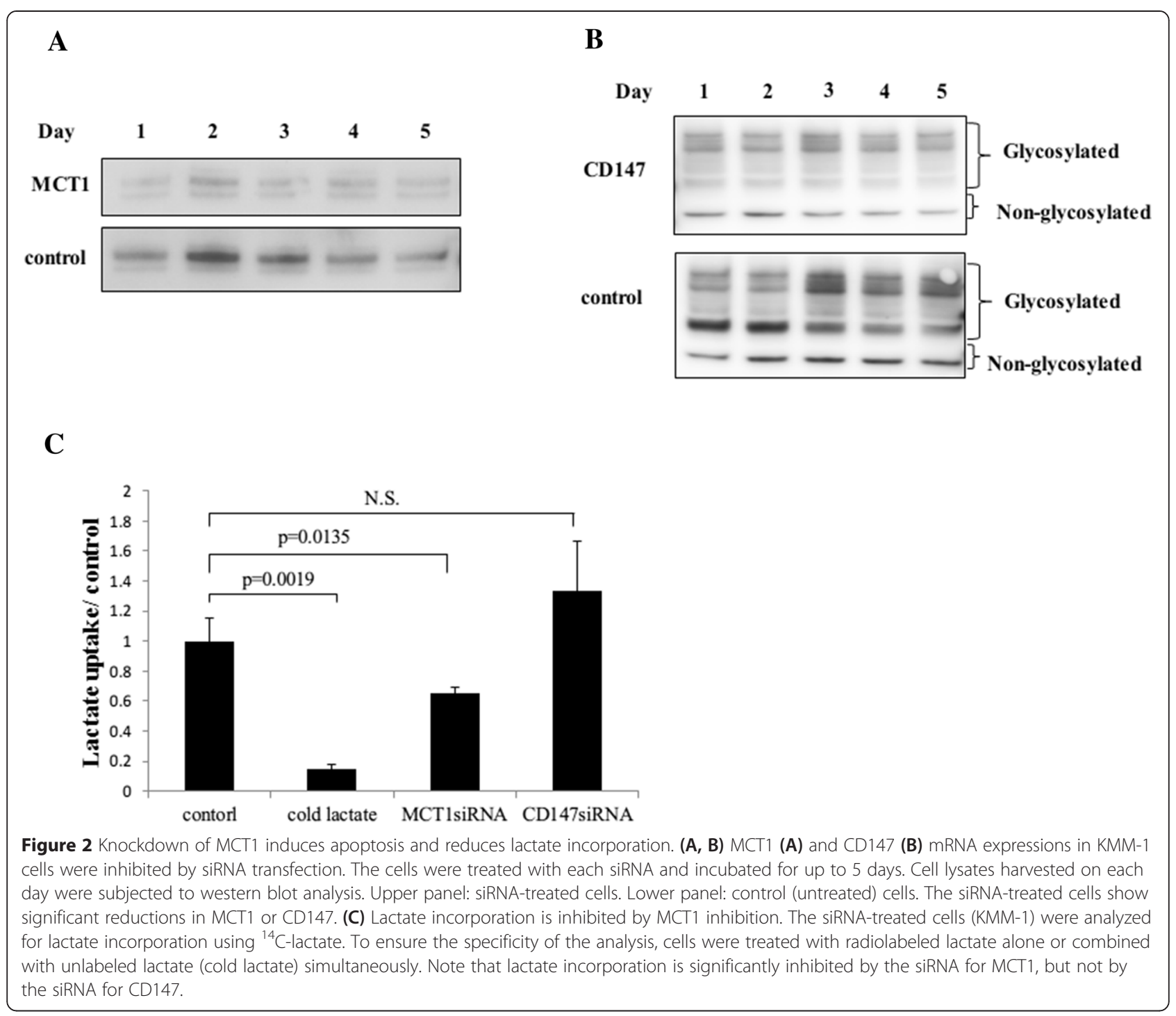

MM cases in which MM cells are depending on Reverse Warburg Effect. Because lactate does not seem to provide to a large contribution for resting normal cells, this modality should provide efficacy that is relatively specific to cancer cells with minimal toxic effects toward normal tissues.

\section{Conclusions}

We present here that lactate is produced by MM cell lines and stromal cells, and contributes to the survival of such MM cells in autocrine or paracrine manners. Lactate incorporation is dependent on MCT1. Suppression of lactate incorporation by targeting MCT1 may provide a novel therapeutic strategy for MM.

\section{Materials and methods}

\section{Cells and cell culture}

Human myeloma cell lines KMS-12BM (12BM) [30], KMS-12PE (12PE) [30], U266 [31], RPMI8226 [32],
KMM-1 [33], and KHM11 [34] were cultured in RPMI1640 containing $10 \% \mathrm{FBS}$ at $37^{\circ} \mathrm{C}$ under $5 \% \mathrm{CO} 2$. Usage of isolated myeloma cells from bone marrow samples were approved by Ethical Committee of Kumamoto University.

\section{Inhibitors}

Dichloroacetate (DCA) and $\alpha$-cyano-4-hydroxycinnamic acid $(\mathrm{CHC})$ were purchased from Sigma-Aldrich (St Louis, MO, USA), and dissolved in phosphate-buffered saline and dimethyl sulfoxide (DMSO), respectively.

\section{Measurement of lactate}

Lactate concentrations were evaluated using a lactate meter (Lactate Pro2; Arkray, Kyoto, Japan), which electronically analyzed potassium ferrocyanide converted from ferricyanide by lactate. 


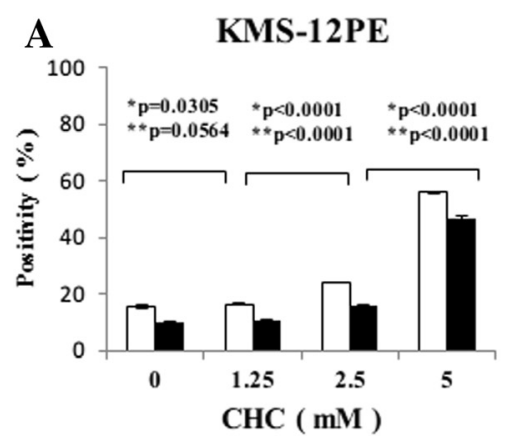

\section{KMM1}
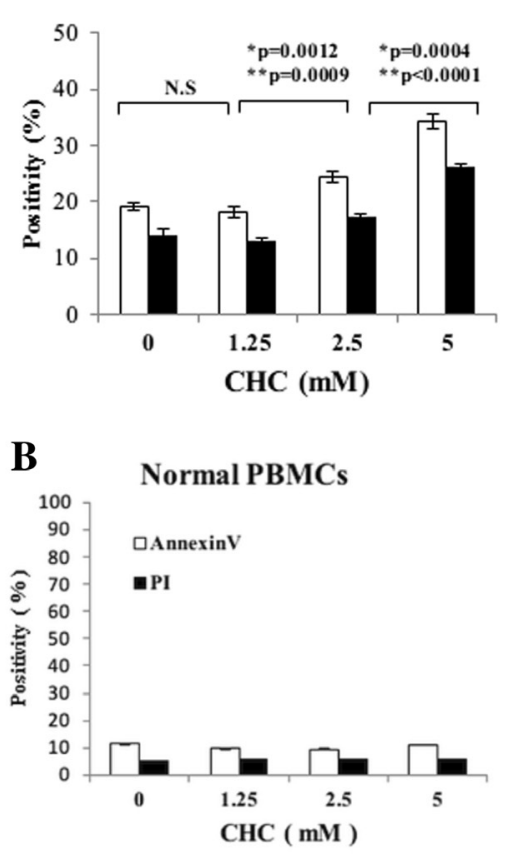

D

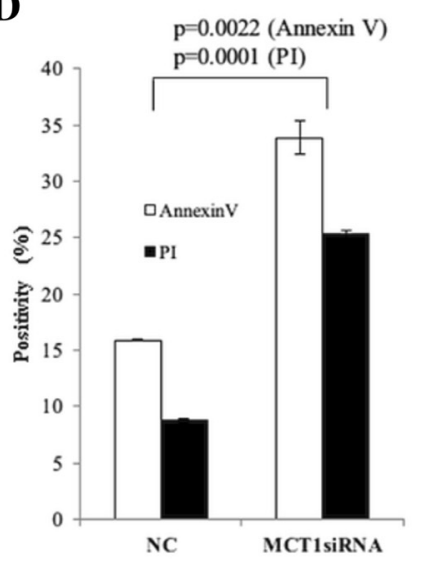

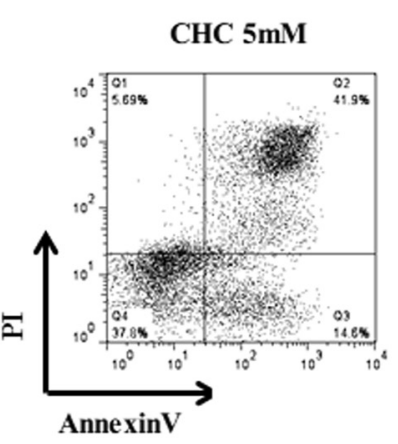

CHC 5mM

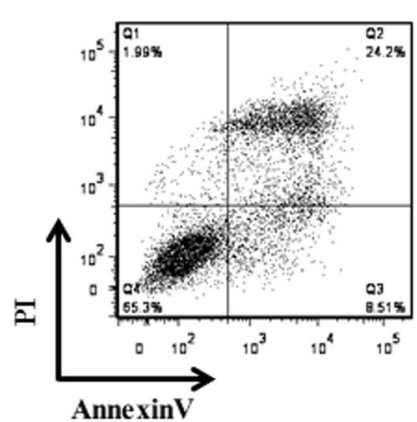

C

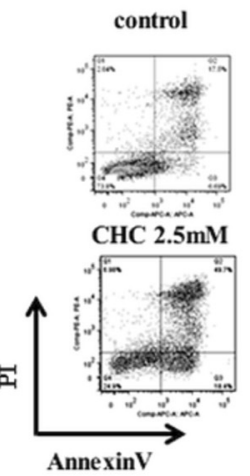

CHC $1.25 \mathrm{mM}$

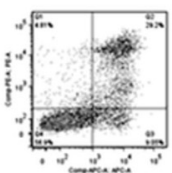

CHC 5.0mM

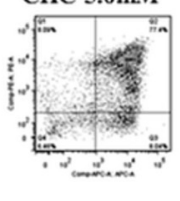

AnnexinV

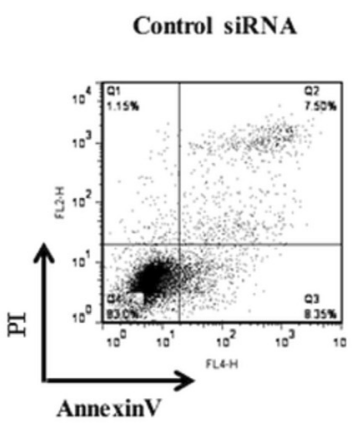

MCT1 siRNA day 5

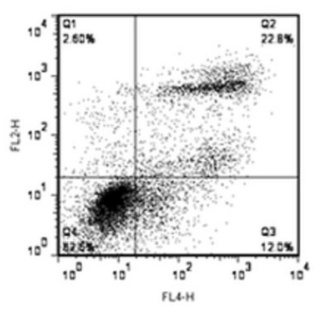

Figure $\mathbf{3}$ (See legend on next page.) 
(See figure on previous page.)

Figure $\mathbf{3}$ Induction of apoptosis in myeloma cells by modulation of MCT1. (A) Induction of apoptosis by CHC. The myeloma cell lines KMS-12PE (upper panels) and KMM-1 (lower panels) were treated with CHC at 0, 1.25, 2.5, or $5 \mathrm{mM}$ for $24 \mathrm{~h}$ and then stained with Annexin V/PI for flow cytometry analysis. Treatment with CHC induces Annexin V-positive (open bars) and PI-positive (filled bars) populations in a dose-dependent manner. ${ }^{*} p$ values for annexin $V_{i}{ }^{* *} p$ values for PI. Representative raw data of the flow cytometry analyses are shown in the right panels. (B) $\mathrm{CHC}$ does not induce apoptosis in normal PBMCs. PBMCs were treated with CHC as described for (A), and do not undergo apoptosis. (C) CD138 positive cells obtained from a MM patient were treated with $\mathrm{CHC}$ at $0,1.25,2.5$, or $5 \mathrm{mM}$ for $24 \mathrm{~h}$ and then stained with Annexin V/PI for flow cytometry analysis. CHC induced apoptosis in myeloma cells obtained from a MM patient in a dose dependent manner. (D) MCT1 knockdown by siRNA results in induction of apoptosis. KMM-1 cells were treated with each siRNA and incubated for up to 5 days. On day 5, cells were subjected to Annexin V/PI staining. Amount of apoptotic cells are quantified and shown in the left panel. Results of FACS analysis are shown in the right panel. Knockdown of MCT1 shows significant induction of apoptosis.

CDNA synthesis and real-time PCR

RNA was extracted from myeloma cells using TRIzol reagent (Invitrogen, Carlsbad, CA, USA). cDNA synthesis was performed using a SuperScript First-Standard Synthesis System (Invitrogen) according to the manufacturer's protocol. Quantitative PCR analyses were performed with Assay-on- Demand primers and Taqman Universal PCR Master Mix Reagent (Applied Biosystems, Foster City, NJ, USA). The samples were analyzed using an $\mathrm{ECO}^{\mathrm{m}}$ Real-Time PCR System (Illumina, San Diego, CA, USA). The $\Delta \Delta \mathrm{Ct}$ method was employed to analyze the relative changes in gene expression as previously described [35], with $A C T B$ as a normalization control. The following primers were used to quantify the expression of MCT1 and actin, respectively: SLC16A1 (Hs00161826_m1); and ACTB (Hs99999903_m1).

\section{Western blot analysis}

Cell lysates were prepared using M-PER Mammalian Protein Extraction Reagent (Pierce Biotechnology Inc., Rockford, IL, USA) after addition of Halt EDTA-free phosphatase inhibitor cocktail and Halt protease inhibitor cocktail (both from Pierce Biotechnology Inc.). Quantification of total protein was performed with a Pierce BCA Protein Assay Kit (Thermo Scientific, Waltham, MA, USA), and equal amounts of protein were used for analysis. The cell lysates were separated in NuPAGE Bis-Tris precast gels (Invitrogen) and transferred to PVDF membranes. The membranes were blocked with 5\% non-fat dry milk dissolved in Tris-buffered saline (TBS) containing $0.5 \%$ Tween-20 (TBS-T) for $1 \mathrm{~h}$ at room temperature, and then incubated with primary antibodies at $4^{\circ} \mathrm{C}$ for $18 \mathrm{~h}$. The following primary antibodies were used: anti-MCT1

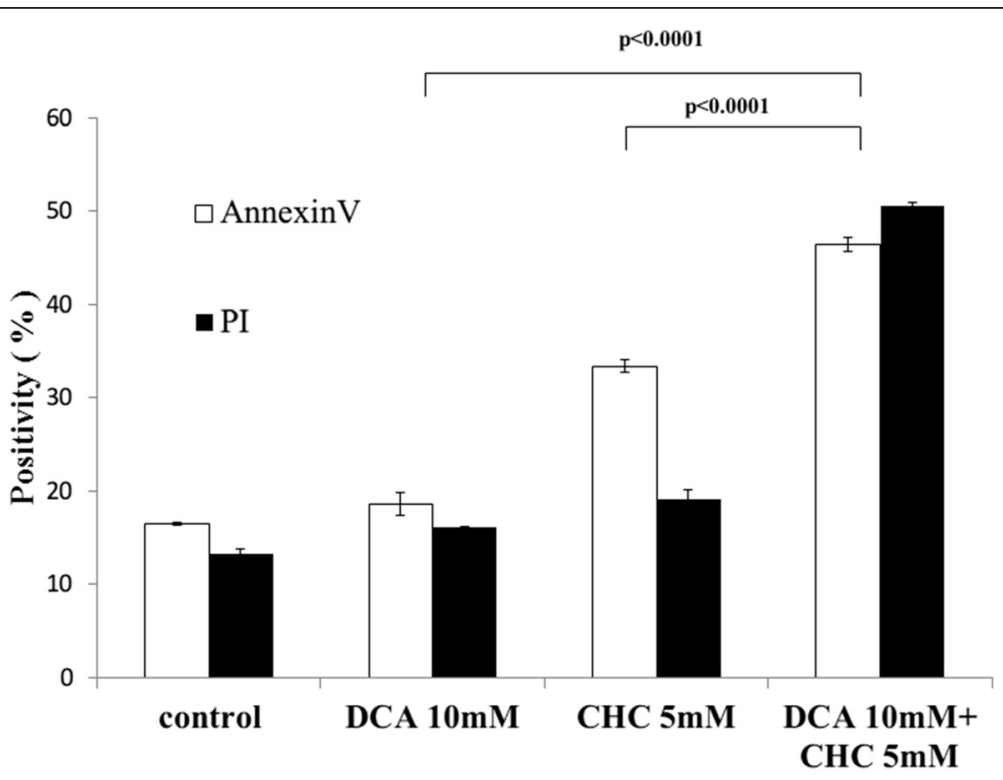

Figure 4 Combined treatment of CHC with DCA increases cell death. KMM1 cells were treated with $\mathrm{CHC}$ or DCA alone or the combination of $\mathrm{CHC}$ and DCA, followed by Annexin V/PI analysis. CHC and DCA each induce apoptosis alone, and the apoptosis is enhanced by the combined treatment $(p<0.0001$, Annexin $\mathrm{V}$ or PI). 


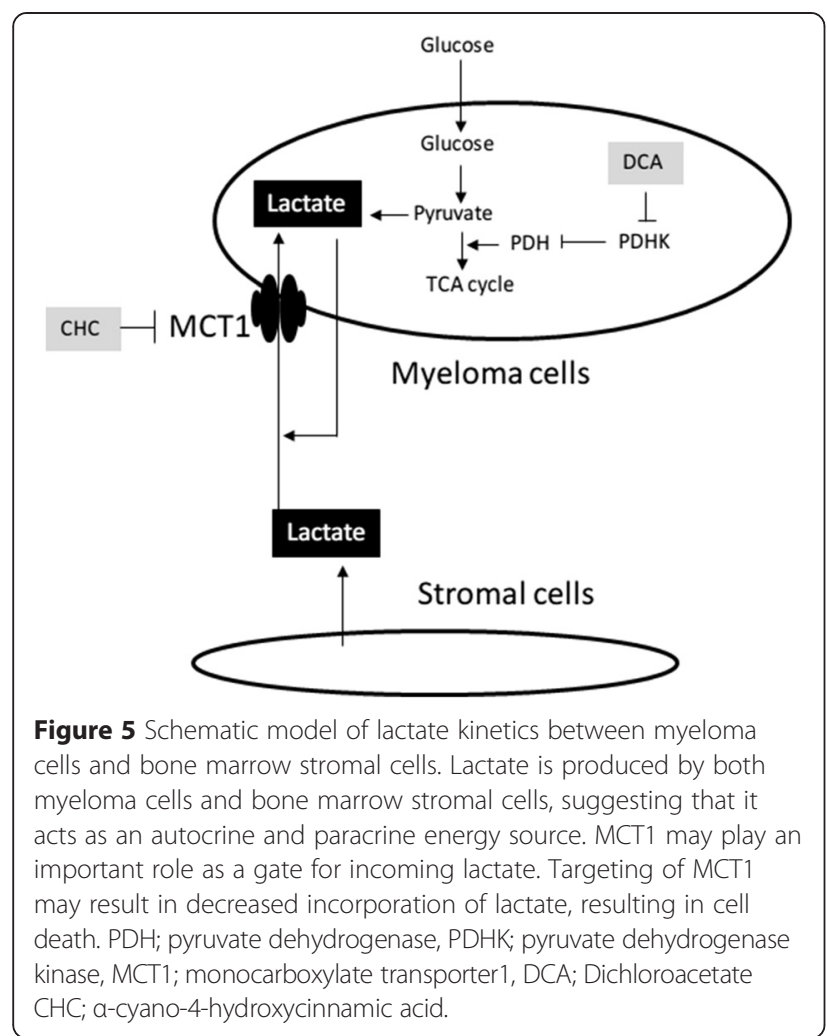

(Santa Cruz Biotechnology, Santa Cruz, CA, USA; sc365501; 1:500), anti-CD147 (Cell Signaling Technology, Beverly, MA, USA; \#12314; 1:250), and anti-ACTB (Santa Cruz Biotechnology; sc-8432; 1:1000). After washing with TBS-T, the membranes were incubated with a horseradish peroxidase-conjugated secondary antibody (GE Healthcare, Little Chalfont, UK) for $1 \mathrm{~h}$ at room temperature. The antibody-bound proteins were visualized using ECL-prime Western Blotting Detection Reagent (GE Healthcare) and an LAS-1000 Bio-image Analyzer (GE Healthcare).

The intensity of the western blot signals was quantified by densitometry using image $\mathrm{j}$.

\section{Analysis of apoptosis}

The myeloma cell lines were incubated in the presence of DCA or CHC for $24 \mathrm{~h}$. Apoptosis in the myeloma cell lines was quantified by staining with Annexin V-allophycocyanin (Molecular Probes, Eugene, OR, USA) and propidium iodide (PI) (MBL, Nagoya, Japan). The samples were analyzed by flow cytometry (FACSCalibur or FACSVerse; Becton Dickson, San Jose, CA, USA).

\section{RNA interference experiments}

An oligonucleotide targeting human SLC16A1 (5'-CAG CAGTATCCTGGTGAATAA-3'; siSLC16A1) was purchased from Qiagen (Valencia, CA, USA). Transfections were performed using Hiperfect Transfection Reagent (Qiagen) according to the manufacturer's protocol. Briefly, $2 \times 10^{5} \mathrm{KMM}-1$ cells in $100 \mu \mathrm{L}$ of medium were seeded into 24-well plates and transfected with $750 \mathrm{ng}$ of siSLC16A1 or control siRNA.

\section{Lactate uptake assay}

On day 2 after siRNA transfection, KMM-1 cells were incubated in uptake buffer (10 mM HEPES, $5 \mathrm{mM}$ $\mathrm{KCl}, 150 \mathrm{mM} \mathrm{NaCl}, 1 \mathrm{mM} \mathrm{MgCl} 2, \mathrm{pH}$ 7.5) containing ${ }^{14} \mathrm{C}$-lactate (PerkinElmer, Waltham, MA, USA) for $1 \mathrm{~h}$ at $37^{\circ} \mathrm{C}$. Uptake was stopped by incubating the cells at $4^{\circ} \mathrm{C}$, and the cells were washed twice using $200 \mu \mathrm{L}$ of uptake buffer. The cells were then lysed in $200 \mu \mathrm{L}$ of uptake buffer containing 1\% SDS and the cell lysates were collected into scintillation vials for quantification of ${ }^{14} \mathrm{C}$-lactate uptake. To ensure selective incorporation of lactate, some cells were simultaneously treated with ${ }^{14} \mathrm{C}$-lactate and unlabeled lactate $(10 \mathrm{mM})$.

\section{Statistical analysis}

The data were analyzed statistically by Student's $t$-test using Statflex version 6 (Artech Co. Ltd., Osaka, Japan). Values of $\mathrm{p}<0.05$ were considered statistically significant.

\section{Abbreviations \\ (MM): Multiple myeloma; (MCTs): Monocarboxylate transporters; (CHC): a-cyano-4-hydroxycinnamic acid; (DCA): Dichloroacetate; (DMSO): Dimethyl} sulfoxide; (TBS): Tris-buffered saline.

\section{Competing interests}

The authors declare that they have no competing interests.

\section{Authors' contributions}

SF, NW, and YK performed experiments. YO, YK, SE, NN, and NU collected samples form MM cases. $\mathrm{HH}$ and SF conducted and designed the experiments. SF wrote whole manuscript under supervision of $\mathrm{HH}$. $\mathrm{HM}$ supervised the experiments. All authors read and approved the final manuscript.

\section{Acknowledgments}

This work was partly funded by a grant from the Amyloidosis Research Committee from the Ministry of Health, Labour, and Welfare, Japan

Received: 4 March 2015 Accepted: 2 April 2015

Published online: 21 April 2015

\section{References}

1. Kim JW, Dang CV. Cancer's molecular sweet tooth and the Warburg effect. Cancer Res. 2006;66:8927-30. doi:10.1158/0008-5472.CAN-06-1501.

2. Brizel DM, Schroeder T, Scher RL, Walenta S, Clough RW, Dewhirst MW, et al. Elevated tumor lactate concentrations predict for an increased risk of metastases in head-and-neck cancer. Int J Radiat Oncol Biol Phys. 2001:51:349-53.

3. Walenta S, Wetterling M, Lehrke M, Schwickert G, Sundfor K, Rofstad EK, et al. High lactate levels predict likelihood of metastases, tumor recurrence, and restricted patient survival in human cervical cancers. Cancer Res. 2000;60:916-21.

4. Quennet V, Yaromina A, Zips D, Rosner A, Walenta S, Baumann M, et al. Tumor lactate content predicts for response to fractionated irradiation of human squamous cell carcinomas in nude mice. Radiother Oncol. 2006;81:130-5. doi:10.1016/j.radonc.2006.08.012. 
5. Kennedy KM, Dewhirst MW. Tumor metabolism of lactate: the influence and therapeutic potential for MCT and CD147 regulation. Future Oncol. 2010;6:127-48. doi:10.2217/fon.09.145.

6. Draoui N, Feron O. Lactate shuttles at a glance: from physiological paradigms to anti-cancer treatments. Dis Model Mech. 2011;4:727-32. doi:10.1242/dmm.007724.

7. Halestrap AP. The monocarboxylate transporter family-Structure and functional characterization. IUBMB Life. 2012;64:1-9. doi:10.1002/iub.573.

8. Halestrap AP, Meredith D. The SLC16 gene family-from monocarboxylate transporters (MCTs) to aromatic amino acid transporters and beyond. Pflugers Arch. 2004;447:619-28. doi:10.1007/s00424-003-1067-2.

9. Kirk P, Wilson MC, Heddle C, Brown MH, Barclay AN, Halestrap AP. CD147 is tightly associated with lactate transporters MCT1 and MCT4 and facilitates their cell surface expression. EMBO J. 2000;19:3896-904. doi:10.1093/emboj/19.15.3896

10. Wilson MC, Meredith D, Halestrap AP. Fluorescence resonance energy transfer studies on the interaction between the lactate transporter MCT1 and CD147 provide information on the topology and stoichiometry of the complex in situ. J Biol Chem. 2002;277:3666-72. doi:10.1074/jbc.M109658200.

11. Nabeshima K, Iwasaki H, Koga K, Hojo H, Suzumiya J, Kikuchi M. Emmprin (basigin/CD147): matrix metalloproteinase modulator and multifunctional cell recognition molecule that plays a critical role in cancer progression. Pathol Int. 2006;56:359-67. doi:10.1111/j.1440-1827.2006.01972.x.

12. Pinheiro C, Longatto-Filho A, Azevedo-Silva J, Casal M, Schmitt FC, Baltazar F. Role of monocarboxylate transporters in human cancers: state of the art. J Bioenerg Biomembr. 2012;44:127-39. doi:10.1007/s10863-012-9428-1.

13. Walters DK, Arendt BK, Jelinek DF. CD147 regulates the expression of MCT1 and lactate export in multiple myeloma cells. Cell Cycle. 2013;12:3175-83. doi:10.4161/cc.26193.

14. Fujiwara S, Kawano Y, Yuki H, Okuno Y, Nosaka K, Mitsuya H, et al. PDK1 inhibition is a novel therapeutic target in multiple myeloma. $\mathrm{Br} J$ Cancer. 2013;108:170-8. doi:10.1038/bjc.2012.527.

15. Sonveaux P, Vegran F, Schroeder T, Wergin MC, Verrax J, Rabbani ZN, et al. Targeting lactate-fueled respiration selectively kills hypoxic tumor cells in mice. J Clin Invest. 2008;118:3930-42. doi:10.1172/Jci36843.

16. Doherty JR, Cleveland JL. Targeting lactate metabolism for cancer therapeutics. J Clin Invest. 2013;123:3685-92. doi:10.1172/JCI69741.

17. Martinez-Outschoorn UE, Whitaker-Menezes D, Valsecchi M, Martinez-Cantarin MP, Dulau-Florea A, Gong J, et al. Reverse Warburg effect in a patient with aggressive B-cell lymphoma: is lactic acidosis a paraneoplastic syndrome? Semin Oncol. 2013;40:403-18. doi:10.1053/j.seminoncol.2013.04.016.

18. Busk M, Walenta S, Mueller-Klieser W, Steiniche T, Jakobsen S, Horsman MR, et al. Inhibition of tumor lactate oxidation: consequences for the tumor microenvironment. Radiother Oncol. 2011;99:404-11. doi:10.1016/ j.radonc.2011.05.053.

19. Hirschhaeuser F, Sattler UG, Mueller-Klieser W. Lactate: a metabolic key player in cancer. Cancer Res. 2011;71:6921-5. doi:10.1158/0008-5472.CAN-11-1457.

20. Walenta S, Chau TV, Schroeder T, Lehr HA, Kunz-Schughart LA, Fuerst A, et al. Metabolic classification of human rectal adenocarcinomas: a novel guideline for clinical oncologists? J Cancer Res Clin Oncol. 2003;129:321-6. doi:10.1007/s00432-003-0450-x.

21. Yokota H, Guo J, Matoba M, Higashi K, Tonami H, Nagao Y. Lactate, choline, and creatine levels measured by vitro $1 \mathrm{H}-\mathrm{MRS}$ as prognostic parameters in patients with non-small-cell lung cancer. J Magn Reson Imaging. 2007:25:992-9. doi:10.1002/jmri.20902.

22. Kang KW, Im YB, Go WJ, Han HK. C-myc amplification altered the gene expression of ABC- and SLC-transporters in human breast epithelial cells. Mol Pharm. 2009;6:627-33. doi:10.1021/mp800116f.

23. Coller HA, Grandori C, Tamayo P, Colbert T, Lander ES, Eisenman RN, et al. Expression analysis with oligonucleotide microarrays reveals that MYC regulates genes involved in growth, cell cycle, signaling, and adhesion. Proc Natl Acad Sci U S A. 2000;97:3260-5.

24. Schuhmacher $M$, Kohlhuber F, Holzel M, Kaiser C, Burtscher $H$, Jarsch $M$, et al. The transcriptional program of a human B cell line in response to Myc. Nucleic Acids Res. 2001;29:397-406.

25. Doherty JR, Yang C, Scott KE, Cameron MD, Fallahi M, Li W, et al. Blocking lactate export by inhibiting the Myc target MCT1 Disables glycolysis and glutathione synthesis. Cancer Res. 2014;74:908-20. doi:10.1158/00085472. CAN-13-2034.

26. Zhao Z, Wu MS, Zou C, Tang Q, Lu J, Liu D, et al. Downregulation of MCT1 inhibits tumor growth, metastasis and enhances chemotherapeutic efficacy in osteosarcoma through regulation of the NF-kappaB pathway. Cancer Lett. 2014;342:150-8. doi:10.1016/j.canlet.2013.08.042.

27. Miranda-Goncalves V, Honavar M, Pinheiro C, Martinho O, Pires MM Pinheiro C, et al. Monocarboxylate transporters (MCTs) in gliomas: expression and exploitation as therapeutic targets. Neuro Oncol. 2013;15:172-88. doi:10.1093/neuonc/nos298.

28. Kumar A, Kant S, Singh SM. Targeting monocarboxylate transporter by alpha-cyano-4-hydroxycinnamate modulates apoptosis and cisplatin resistance of Colo205 cells: implication of altered cell survival regulation. Apoptosis. 2013;18:1574-85. doi:10.1007/s10495-013-0894-7.

29. Diers AR, Broniowska KA, Chang CF, Hogg N. Pyruvate fuels mitochondrial respiration and proliferation of breast cancer cells: effect of monocarboxylate transporter inhibition. Biochem J. 2012;444:561-71. doi:10.1042/BJ20120294.

30. Ohtsuki T, Yawata Y, Wada H, Sugihara T, Mori M, Namba M. Two human myeloma cell lines, amylase-producing KMS-12-PE and amylase-non-producing KMS-12-BM, were established from a patient, having the same chromosome marker, t(11;14)(q13;q32). Br J Haematol. 1989;73:199-204.

31. Ikeyama S, Nakagawa S, Arakawa M, Sugino H, Kakinuma A. Purification and characterization of lgE produced by human myeloma cell line, U266. Mol Immunol. 1986;23:159-67.

32. Matsuoka Y, Moore GE, Yagi Y, Pressman D. Production of free light chains of immunoglobulin by a hematopoietic cell line derived from a patient with multiple myeloma. Proc Soc Exp Biol Med. 1967;125:1246-50.

33. Togawa A, Inoue N, Miyamoto K, Hyodo H, Namba M. Establishment and characterization of a human myeloma cell line (KMM-1). Int J Cancer. 1982;29:495-500

34. Hata H, Matsuzaki H, Sonoki T, Takemoto S, Kuribayashi N, Nagasaki A, et al. Establishment of a CD45-positive immature plasma cell line from an aggressive multiple myeloma with high serum lactate dehydrogenase. Leukemia. 1994;8:1768-73.

35. Livak KJ, Schmittgen TD. Analysis of relative gene expression data using real-time quantitative PCR and the 2(-Delta Delta C(T)) Method. Methods. 2001;25:402-8. doi:10.1006/meth.2001.1262.

\section{Submit your next manuscript to BioMed Central and take full advantage of:}

- Convenient online submission

- Thorough peer review

- No space constraints or color figure charges

- Immediate publication on acceptance

- Inclusion in PubMed, CAS, Scopus and Google Scholar

- Research which is freely available for redistribution 